\title{
AS ASSEMBLEIAS ESTUDANTIS E O EXERCÍCIO DA GESTÃO DEMOCRÁTICA
}

\section{ASAMBLEAS ESTUDIANTILES Y EL EJERCICIO DE GESTIÓN DEMOCRÁTICA}

STUDENT ASSEMBLEIES AND DEMOCRATIC MANAGEMENT EXERCISE

\author{
Emerson Sandro Silva SARAIVA ${ }^{1}$ \\ Thalysson Kelvyn do MONTE ${ }^{2}$
}

\begin{abstract}
RESUMO: As discussões sobre questões relacionadas à democracia, sobretudo a como exercêla, são importantes na sociedade neoliberal na qual nos encontramos. Em razão da crise democrática atravessada pela valorização do mercado e minimização de direitos sociais, as assembleias estudantis surgem como campos de debates pertinentes à sociedade. A temática desenvolveu-se neste trabalho através de pesquisa qualitativa, de base dialética, associada a estudo de caso, que traz realidade específica com características de um todo social. Diálogos com Lima (2018), Marx (2003), Paro (2016), Souza (2017), entre outros, revelaram a importância das assembleias como instrumentos de construção das sociedades democráticas em tempos de opressão e determinismo social.
\end{abstract}

PALAVRAS-CHAVE: Assembleias estudantis. Gestão democrática. Participação. Democracia.

RESUMEN: Las discusiones sobre temas relacionados con la democracia, ante todo con cómo ejercerla, son importantes en la sociedad neoliberal en la cual nos encontramos. En virtud de la crisis democrática atravesada por cuenta de la valorización del mercado y la minimización de los derechos sociales, las asambleas estudiantiles surgen como campos de debate pertinentes para la sociedad. La temática ha sido desarrollada en este trabajo a través de la investigación cualitativa, de fundamentación dialéctica, vinculada a análisis de caso, que infiere realidad específica con características de un todo social. Diálogos con Lima (2018), Marx (2003), Paro (2016), Souza (2017), entre otros, revelaron la importancia de las asambleas como instrumentos de construcción de sociedades democráticas en tiempos de opresión y determinismo social.

PALABRAS CLAVE: Asambleas estudiantiles. Gestión democrática. Participación. Democracia

ABSTRACT: Discussions about democracy related issues, especially how to exercise it, are important in the neoliberal society in which we find ourselves. Because of the democratic crisis, crossed by market valuation end the minimization of social rights, students' assemblies appear as fields of debate relevant to society. The theme of this paper was developed through

${ }^{1}$ Universidade do Estado do Amazonas - (UEA), Manaus - AM - Brasil. Professor adjunto da universidade. ORCID: https://orcid.org/0000-0002-4423-7144. E-mail: esaraiva@uea.edu.br

${ }^{2}$ Universidade do Estado do Amazonas - (UEA), Manaus - AM - Brasil. Acadêmico do curso de Licenciatura em Pedagogia. ORCID: https://orcid.org/0000-0003-3764-4179. E-mail: thalysson@uea.edu.br

RPGE- Revista on line de Política e Gestão Educacional, Araraquara, v. 24, n. 1, p. 164-188, jan./abr., 2020. e-ISSN:1519-9029. 
qualitative research, with dialectical base, associated at case study, which brings specific reality with characteristics of a social whole. Dialogues with Lima (2018), Marx (2003), Paro (2016), Souza (2017), among others, revealed the importance of assemblies as instruments of building democratic societies in times of oppression and social determinism.

KEYWORDS: Student assemblies. Democratic management. Participation. Democracy.

\section{Introdução}

As demandas da sociedade liberal e neoliberal incluem "democracia", política de "gestão democrática" e mercado consumidor, com supostos processos de participação social. Nesses modelos sociais de democracia, as assembleias estudantis surgem como instrumentos de tal participação. Por este viés, assume-se que para a formação de uma sociedade crítica é necessário o exercício do diálogo e da participação. Sendo assim, estes exercícios de aquisição da cidadania podem ser construídos em nível escolar?

Com a redemocratização da sociedade brasileira em meados de 1980, tornou-se fundamental discutir a democracia, as assembleias, a formação dos estudantes, a participação e a gestão democrática na educação. E tais debates continuam pertinentes, uma vez que no Brasil a crise democrática é caraterizada, sobretudo, por constantes ataques aos direitos humanos e básicos da população, com instabilidade das instituições, recorrente corrupção e descrença massiva nos processos eleitorais e políticos.

Nesse sentido, o problema estudado nesta pesquisa está relacionado à participação estudantil na escola, seus modos de atuação e constituição; concepção de assembleias, seus sentidos e contribuições; percepção de gestão democrática e ações estudantis na escola pública pelos sujeitos do espaço escolar.

Mediante inquietações e problemas da sociedade na qual a escola pública está entrelaçada, buscou-se compreender como as assembleias estudantis podem ou não contribuir com o exercício da gestão democrática. Para tanto, realizou-se registros de atividades de assembleias estudantis por meio de anotações em um caderno de campo. A partir daí, analisouse a participação dos sujeitos deste espaço, além de identificar conflitos e contradições que emergem do modelo de democracia ou de sua busca enquanto prática de cidadania.

O universo da pesquisa foi uma escola pública da zona centro-sul de Manaus, escolhida por apresentar uma proposta de ensino pautada na construção da gestão democrática e na participação de sua comunidade. O ponto de destaque foram as vagas para 226 alunos em instituição pública de tempo integral, com efetiva participação de 150 discentes nas assembleias 
que ocorriam durante os intervalos das aulas, em dias alternados, organizadas conforme as problemáticas que surgiam na escola e envolviam aquele corpo social.

A pesquisa ocorreu com participação de 08 professores, 01 gestora, 01 pedagoga, 20 pessoas do corpo técnico e administrativo da escola, contando com serviços gerais, setor de alimentação e segurança, totalizando 162 pessoas envolvidas diretamente no processo. Realizado entre os meses de agosto de 2018 a abril de 2019, o estudo possibilitou-nos não apenas acompanhar os processos e necessidades educativas da instituição, mas também participar das atividades realizadas, sobretudo das assembleias, o que nos proporcionou amplo conhecimento sobre as perspectivas da educação na formação crítica da sociedade.

A escola caracteriza-se com uma das primeiras da região norte a pensar e articular ações de gestão democrática, integrando a comunidade por meio de encontros e assembleias. Fundada em 1987, a instituição escolar localiza-se numa área de igarapés e atende a alunos do ensino fundamental em uma região de extrema vulnerabilidade social. Trata-se de construir cidadania com crianças de baixa renda e de acolher crianças venezuelanas e haitianas através da inclusão social e efetiva matrícula institucional.

Os professores possuem vasto tempo de serviço e formação em pedagogia. Também há na escola professora de Inglês e de Educação Física, que atuam na formação dos estudantes e de si mesmas. Todas as assembleias eram registradas pela escola, com duração de 30 a 40 minutos, e as pautas formadas por meio do debate de ideias, mediante apresentação de problemas. A participação dos alunos é livre, mas precisam ir ao microfone para se pronunciarem por meio de defesa de determinado assunto e, após argumento, atribuir o voto.

Para a análise deste trabalho utilizamos a pesquisa qualitativa em consonância com o materialismo histórico dialético, visto que o método oportuniza capturar o movimento real do objeto de pesquisa (MARX, 2003).

Estudar este movimento da escola, direcionado à construção da cidadania, implica compreender que é necessário ir além das aparências, captando a essência e totalidade do objeto, partindo do real. Neste sentido, é preciso buscar na história a compreensão da realidade em sua relação com o presente, pois, como salienta Marx,

A tradição de todas as gerações passadas é como um pesadelo que comprime cérebro dos vivos. E justamente quando parecem estar empenhados em transformar a si mesmos e as coisas, em criar algo nunca antes visto, exatamente nessas épocas de crise revolucionária, eles conjuram temerosamente a ajuda dos espíritos do passado, tomam emprestado os seus nomes, as suas palavras de ordem, o seu figurino, a fim de representar, com essa vulnerável roupagem tradicional e essa linguagem tomada de empréstimo, as novas cenas da história mundial (MARX, 2011, p. 159). 
Neste sentido, a pseudodemocracia e sua roupagem podem esconder o real e apresentar um ideal de sociedade burguesa, controlada por uma elite dominante com artimanhas de falsos processos democráticos. A atividade de assembleia estudantil poderá representar a quebra destes recursos sórdidos de alienação da sociedade e a escola pública, neste cenário, representa um caminho possível para tal processo mediante a formação crítica e comprometida de professores, alunos e comunidade.

A análise da referida situação dá-se em um contexto particular que faz parte de um todo social, portanto, a pesquisa caracteriza-se como um estudo de caso que, nas Ciências Sociais, é considerado o caminho mais adequado para a investigação de um processo contemporâneo dentro de seu contexto real (YIN, 2001). Os instrumentos ou técnicas de coleta de dados que compuseram a trajetória de investigação foram a pesquisa participante, observação participante, e pesquisa bibliográfica e documental, que auxiliaram na análise das contradições do espaço real e ideal.

Quanto à estruturação do trabalho, o corpo do texto divide-se em 4 tópicos. No primeiro, tratamos sobre o conceito de democracia, pontuando, sobretudo, que no Brasil há excesso de representatividade em detrimento da participação popular, pois mesmo dispositivos previstos na Constituição Federal (1988), como plebiscitos, referendos e iniciativas populares para a efetivação de tal participação, pouco são utilizados.

No segundo momento, abordamos a questão da gestão democrática e da participação, apresentando o conceito de ambas, perpassando brevemente pelo histórico deste modelo de gestão no Brasil, e argumentando que participação se refere a uma de suas principais bases constitutivas.

Já no terceiro tópico, dissertamos sobre o que são assembleias, de forma geral, e o que são assembleias no âmbito escolar, expondo alguns de seus tipos, suas funções primárias e secundárias, bem como sua estrutura/funcionamento.

No quarto e último ponto, temos o relato de campo, no qual apresentamos os resultados da pesquisa empírica realizada na escola supracitada, argumentando que as assembleias estudantis fazem parte de um processo maior de democratização da instituição escolar, isto é, são uma das várias maneiras de colocar em prática tal proposta de gestão, pois possuem como principal contribuição a possibilidade do diálogo e debate de questões e problemas comuns aos envolvidos, algo indispensável não apenas em escolas que se pretendem democráticas, mas para as sociedades. 


\section{Democracia no Brasil: entre a representação e a participação popular}

É de amplo conhecimento que não existe apenas um único conceito ou definição de democracia (SOUZA, 2007), mas, sim, vários, que podem ser bastante semelhantes ou até mesmo contraditórios. Nesse sentido, não se pretende afirmar um conceito indiscutível, mas opta-se por uma das diversas definições existentes, a qual melhor serve aos propósitos do presente estudo. Dessa forma, democracia é considerada como:

regime de governo no qual o poder de tomar importantes decisões políticas está com os cidadãos, que são os componentes da sociedade. Cabe ao povo ou à comunidade discutir, refletir, pensar e encontrar soluções e intervenções para os próprios problemas (DALBÉRIO, 2009, p. 71).

Assume-se este conceito por dar abertura para que os dois tipos principais - mas não únicos - de democracia, a representativa e a participativa, possam coexistir e se complementar. Aqui, portanto, considera-se a democracia representativa como válida, porém bastante limitada, visto que, para que os anseios e necessidades das camadas populares da sociedade sejam atendidos é preciso maior participação tais classes. Necessita-se, portanto, de uma democracia mais participativa, popular, direta, o que traduz a visão de Gadotti (2013, p. 16), ao dizer que "o Estado brasileiro precisa ser menos representativo e mais participativo".

Considera-se democracia representativa aquela que possui limitações, pois muitas vezes os anseios ou necessidades do povo são ignorados ou colocados em segundo plano por quem exerce a representação: presidentes, deputados, vereadores, governadores, prefeitos, etc. Além do fato de que tais pessoas podem representar seus próprios interesses ou de certos grupos dominantes da sociedade, a população brasileira é extremamente diversificada, algo que torna uma representação satisfatória e mais igualitária extremamente complicada, como afirma Gadotti (2013, p. 17):

O Brasil tem uma composição social extremamente diversa e a democracia representativa não dá conta de toda essa diversidade. Cada vez mais cidadãos e cidadãs não se sentem representados no Parlamento e acabam por se desinteressar da política, ausentando-se não só nas eleições, mas da vida cívica e dos espaços de participação e formação política.

A Constituição Federal (BRASIL, 1988), em seu art. $1^{\circ}$, preconiza que "todo o poder emana do povo, que o exerce por meio de representantes eleitos ou diretamente", isto é, de forma representativa e participativa. Embora nossa legislação determine que os dois tipos de democracia possam ocorrer simultaneamente, na prática, a democracia representativa é expressivamente dominante, pois são raros os momentos de participação efetiva do povo nas 
decisões, a exemplo dos plebiscitos, referendos e iniciativas populares, respectivamente previstos nos incisos I, II e III do art. 14 da Carta Magna, como formas de participação direta da população. Afirmar que esses tipos de participação pouco ocorrem trata-se de um eufemismo, pois são, de fato, raríssimos.

De acordo com a Lei ${ }^{\circ}$ 9709/96, também conhecida como Lei da Democracia Direta, tem-se regulamentada a realização desses três tipos de participação direta:

Art. $2^{\mathrm{o}}$ Plebiscito e referendo são consultas formuladas ao povo para que delibere sobre matéria de acentuada relevância, de natureza constitucional, legislativa ou administrativa.

$\S 1$ o O plebiscito é convocado com anterioridade a ato legislativo ou administrativo, cabendo ao povo, pelo voto, aprovar ou denegar o que lhe tenha sido submetido.

$\S 2^{-} \mathrm{O}$ referendo é convocado com posterioridade a ato legislativo ou administrativo, cumprindo ao povo a respectiva ratificação ou rejeição.

Art. 13. A iniciativa popular consiste na apresentação de projeto de lei à Câmara dos Deputados, subscrito por, no mínimo, um por cento do eleitorado nacional, distribuído pelo menos por cinco Estados, com não menos de três décimos por cento dos eleitores de cada um deles.

Os plebiscitos e referendos, para serem realizados, dependem de convocação por meio de decreto do Poder Legislativo, que necessita da aprovação de, no mínimo, um terço dos membros da Câmara ou do Senado (BRASIL, 1998). Já as iniciativas populares partem do povo, mas apresentam-se extremamente difíceis, pois necessitam de uma quantidade considerável de pleiteantes para efetivação.

No Brasil, os plebiscitos, referendos e iniciativas populares, como dito, ocorreram raríssimas vezes, sendo válido rememorar esses parcos acontecimentos, uma vez que "o presente não se explica sem o passado" (SOUZA, 2017, p. 13).

De acordo com Fornazieri (2013), na história brasileira recente tivemos apenas três consultas de caráter nacional, feitas por meio de plebiscitos ou referendos. A primeira delas foi em 1963, quando a população foi convocada para a realização de um plebiscito sobre o sistema de governo, sendo que as opções eram presidencialismo e parlamentarismo. 30 anos depois, em 1993, outro plebiscito foi realizado, o povo precisou decidir entre monarquia ou república, parlamentarismo ou presidencialismo (FORNAZIERI, 2013). Na primeira, venceu o presidencialismo; na segunda, república e presidencialismo.

Ainda segundo Fornazieri (2013), em 2005, realizou-se o único referendo da história brasileira recente, para decidir acerca de um dos artigos do chamado Estatuto do Desarmamento, sancionado em 2003 pelo presidente Lula, que necessitava da anuência do povo para vigorar, em virtude de sua importância. Neste referendo, colocou-se a seguinte questão 
para votação: “o comércio de armas de fogo e munição deve ser proibido no Brasil?”. A população optou expressivamente pelo "não", e o artigo, que determinava a proibição da comercialização de armas de fogo em todo o território nacional, não entrou em vigor.

Quanto às iniciativas populares, como dito, são bastante difíceis tanto de propor quanto de aprovar. De acordo com o site/portal do Senado Federal (2017), ao longo de nossa história, apenas 04 projetos de lei desta natureza foram aprovados em âmbito federal, todos pósConstituição de 1988: Lei Daniella Perez (Lei 8.930/1996); Lei de Combate à Compra de Votos (Lei 9.840/1999); Lei do Fundo Nacional de Habitação de Interesse Social (Lei 11.124/2005); e Lei da Ficha Limpa (Lei Complementar 135/2010), sendo esta última a mais importante e expressiva de todas, pois foi responsável, desde sua promulgação, por barrar milhares de candidaturas em eleições municipais, estaduais e nacionais.

Evidentemente, esses três tipos de participação direta da população não são os únicos, pois existem outros meios. Contudo, por estarem contemplados em nossa Carta Magna há algumas décadas, ativemo-nos apenas a eles, uma vez que atestam que mesmo as formas de participação previstas em lei pouco são utilizadas na prática.

Ainda sobre a questão da democracia, é válido realizar outras reflexões. Apple e Beane (2001) argumentam que não é de surpreender que a palavra “democracia” esteja sendo bastante ouvida atualmente, considerando sua importância. Contudo, os autores alertam para o uso ambíguo do termo:

\footnotetext{
Pode-se entender que as alegações de democracia sejam usadas para embasar movimentos por direitos civis, por maiores privilégios eleitorais e proteção ao direito de livre expressão. Mas a democracia também é usada para favorecer as causas das economias de livre mercado e dos fiadores para opções escolares, e para defender o predomínio dos dois maiores partidos políticos. Ouvimos a defesa da democracia usada inúmeras vezes, todos os dias, para justificar praticamente tudo o que as pessoas querem fazer: "Vivemos numa democracia, certo?" (APPLE; BEANE, 2001, p. 15).
}

Como visto, a retórica da democracia é utilizada, de um lado, para causas justas, mas, de outro, para justificar atitudes bastante questionáveis e até mesmo inaceitáveis, pois democracia não é cada um fazer o que bem entende, de forma ilimitada, mas fazer o que quer dentro do que é combinado que pode ser feito (CORTELLA, 2019). Em uma sociedade que se logra ser democrática, é inconcebível, por exemplo, que as pessoas possam fazer justiça com as próprias mãos (ARAÚJO, 2015).

Embora Apple e Beane (2001) tratem mais especificamente sobre os Estados Unidos, país em que residem, um cenário bastante similar ao descrito é identificado no Brasil, pois a democracia vem sendo uma das pautas mais discutidas, contestadas e ameaçadas no país, 
sobretudo desde as chamadas Jornadas de Junho - grandes manifestações ocorridas em 2013 que culminaram especialmente em alguns acontecimentos: em 2016, a derrubada da presidente Dilma Rousseff por meio de um polêmico processo de impeachment, considerado golpe por muitos; os ataques sofridos pelas camadas mais pobres da sociedade no governo de Michel Temer, além das conturbadas eleições de 2018 - especialmente a presidencial -, perpassadas por descrença e desconfiança nos processos democráticos, que resultaram, sobretudo, na ascensão ao poder executivo de um político com fortes traços autoritários: Jair Bolsonaro.

\section{Gestão democrática e participação}

Com a questão da democracia esclarecida, passemos à discussão sobre gestão democrática, a partir de dois motivos centrais: em primeiro lugar, a democratização da escola só faz sentido quando articulada com o processo de democratização da sociedade como um todo (SOUZA, 2015); em segundo, a forma como é praticada a democracia na sociedade brasileira em muito reflete na forma com que é exercida no espaço escolar, visto que este não é uma instituição isolada do restante do país, mas, sim, parte dele (PARO, 2016).

A gestão democrática, assim como a democracia, também não possui apenas um conceito, mas, para os fins deste estudo, consideramos sua definição como sendo:

\footnotetext{
Um processo de aprendizado e de luta política que não se circunscreve aos limites da prática educativa, mas vislumbra, nas especificidades da prática social e de sua relativa autonomia, a possibilidade de criação de canais de efetiva participação e de aprendizado no "jogo democrático" e, consequentemente, do repensar nas estruturas de poder autoritário que permeiam as relações sociais e, no seio delas, as práticas educativas (DOURADO, 2013, p. 79).
}

Neste conceito, uma palavra merece destaque: processo. Gestão democrática é um processo, não algo que pode ser feito ou atingido de uma hora para outra, apenas seguindo um receituário pronto e infalível. Neste processo, como observado, devem ser criados meios de verdadeira participação no jogo democrático, e também de aprendizado. Por conseguinte, precisam ser questionadas as estruturas autoritárias que há muito perpassam nossas relações, visto que o Brasil como o conhecemos nasceu de uma situação de autoritarismo, e, ao longo da história, passou por momentos extremamente autoritários, como a Era Vargas - em especial a segunda metade, chamada de Estado Novo -, nas décadas de 1930 e 1940; e a ditadura civilmilitar, entre as décadas de 1960 e 1980. 
No Brasil, a gestão democrática ganhou força nos anos de 1970 e 1980, no contexto da redemocratização do país, ou seja, no período de transição da ditadura civil-militar para o regime democrático. Entre 1987 e 1988 foi realizada a Assembleia Nacional Constituinte, na qual participaram vários movimentos sociais brasileiros, partidos políticos de massa, sindicatos e até mesmo setores progressistas da Igreja Católica, vinculados à Pastoral da Terra (HASCKEL, 2007). Tais movimentos lutavam por direitos humanos, terra, anistia, redemocratização da sociedade, democratização da educação, etc. (HASCKEL, 2007).

No bojo das discussões sobre democracia, estava a questão da gestão democrática das escolas, que acabou por figurar na Constituição de 1988, no inciso VII do art. 206, que determina a "gestão democrática do ensino público, na forma de lei” (BRASIL, 1988). Como visto, a redação da lei foi feita de forma bastante simples e direta, configurando uma conquista parcial (ADRIÃO; CAMARGO, 2007) e precisou ser complementada posteriormente, algo que ocorreu apenas por meio da Lei $n^{\circ}$ 9.394, de 1996, que estabelece as Diretrizes e Bases da Educação Nacional (LDB, 1996).

O inciso VIII do art. $3^{\circ}$ da LDB apenas ratifica o que já preconizava a Constituição em seu art. 206, determinando a "gestão democrática do ensino público na forma de lei e da legislação dos sistemas de ensino". O art. 14 vai além e diz:

Os sistemas de ensino definirão as normas da gestão democrática do ensino público na educação básica, de acordo com as suas peculiaridades e conforme os seguintes princípios:

I - Participação dos profissionais da educação na elaboração do projeto pedagógico da escola;

II - Participação das comunidades escolar e local em conselhos escolares ou equivalentes (BRASIL, 1996).

Ainda de acordo a LDB, art. 12, inciso VI, as escolas possuem a responsabilidade de articular-se com as famílias e a comunidade, promovendo processos de integração da sociedade com as instituições. Complementando, o art. 13, inciso VI, determina que os professores sejam os responsáveis por essas atividades de articulação.

"Embora pesem seus limites e condicionantes, a LDB é a expressão das lutas efetivadas entre as forças sociais, e apresenta-se como balizador para as políticas educacionais" (DOURADO, 2013, p. 96). Pode-se dizer o mesmo sobre a Constituição de 1988, comumente chamada de Constituição Cidadã.

Contudo, a mera previsão da gestão democrática na legislação não garante sua consecução na prática. Na verdade, esse tipo de suposição possui uma abordagem tradicional, de cariz positivista, que subordina a ação organizacional escolar à mera reprodução de regras 
legais e outras de tipo prescritivo, frequente em estudos de teor legalista e normativista (LIMA, 2018).

Infelizmente a gestão democrática das escolas brasileiras enfrenta diversos problemas para sua consecução, e tem se limitado a um:

movimento de descentralização da tomada de decisão nas políticas públicas pelos órgãos gestores e da descentralização da execução pelas escolas de tarefas predeterminadas; à eleição do diretor, que, em decorrência de diversos fatores, dirige a escola de forma muitas vezes centralizada e centralizadora; à formação de conselhos escolares que se reúnem ocasionalmente apenas para referendar as decisões previamente tomadas pelo diretor ou porque a formalidade burocrática assim o exige; à existência de organização na forma de associações de pais, professores e funcionários ou instituições equivalentes, mas com denominação diversa em cada sistema de ensino, que, em geral, tem assumido função auxiliar na manutenção físico-financeira da escola (SOUZA, 2015, p. 45).

Quando se fala em gestão democrática, uma das principais bases a serem apresentadas - talvez até mesmo a principal - é da participação, que, por sua vez, deve englobar todos os envolvidos no processo educacional: alunos, professores, servidores da escola, pais, sociedade, enfim, toda a comunidade escolar.

De acordo com Habermas (1975, p. 159 apud FERREIRA, 2013, p. 78), “participar significa que todos podem contribuir, com igualdade de oportunidades, nos processos de formação discursiva da vontade". Isto é, "consiste em ajudar a construir comunicativamente o consenso quanto a um plano de ação coletivo" (CATANI; GUTIERREZ, 2013, p. 78). Utilizase estas duas definições de participação, uma vez que se complementam.

Contudo, esta participação enfrenta, principalmente, a ausência de uma cultura democrática não apenas no âmbito escolar, mas da sociedade brasileira como um todo (QUINTERO et al., 2007). Pode-se dizer também que:

o verbo participar, tal qual na sociedade, parece não estar sendo conjugado de modo efetivo na escola, pois participar neste contexto parece ser o oposto de "ficar parado". Participar limita-se a "mexer-se" com bons modos - levantar o dedo para perguntar, para ir ao banheiro, ir ao quadro, ajudar a professora, obedecer às regras, etc. Nesse sentido, a escola escancara seu potencial de reprodutora da ideologia dominante quando imprime na cultura da escola a lei do "manda quem pode, obedece quem tem juízo" (QUINTERO et al., 2007, p. 35).

A discussão sobre a participação, em especial no âmbito escolar, é fundamental no caótico contexto brasileiro atual, que perpassa por violência, exclusão social e miséria, e no qual a população não possui garantia nem mesmo de direitos básicos, como educação e saúde (HASCKEL, 2007). 
Paro (2016) argumenta que a participação de toda a comunidade escolar nos processos de decisão não retira o poder das mãos do diretor - pois ele nunca o teve de fato -, mas, sim, propicia condições melhores para pressionar as instâncias superiores, visto que, sozinho, um diretor não possui tanta força perante o sistema.

A participação nos processos de decisão implica mais do que apenas deliberar sobre um assunto, significa participar da construção, execução e acompanhamento de uma proposta pedagógica (SOUZA, 2015). É exatamente a esta participação que nos referindo quando falamos em "exercício", isto é, "exercício da gestão democrática", neste caso, por meio das assembleias estudantis.

\section{As assembleias: o que são e como funcionam?}

Em nossa sociedade, as assembleias não ocorrem apenas nos espaços escolares. É válido, então, apresentar uma visão mais geral elas. Bobbio (1998, p. 60) é categórico ao afirmar que o termo "assembleia" é normalmente utilizado para indicar "qualquer tipo de reunião de várias pessoas para discutir ou deliberar sobre questões comuns".

Segundo o autor, este termo foi por diversas vezes utilizado pela França ao longo do século XVIII, para indicar o órgão representativo da nação, algo que também foi feito pela Inglaterra em sua história colonial, para indicar os órgãos representativos das colônias americanas. Ainda de acordo com o mesmo estudioso:

No vocabulário político, o termo ocorre tecnicamente com três significados: Assembleia constituinte, para distingui-la da Assembleia legislativa ou Parlamento; regime de Assembleia, para distingui-lo do regime parlamentar em sentido estrito; e Assembleia, para contrapô-la à representação (BOBBIO, 1998, p. 60).

As assembleias, em âmbito escolar, aproximam-se mais do terceiro tipo descrito pelos apontamentos de Bobbio, e vão além, pois, segundo Puig et al. (2000, p. 86), tratam-se do "momento institucional da palavra. O momento em que o coletivo se reúne para refletir, tomar consciência de si mesmo e transformar o que seus membros consideram oportuno, de forma a melhorar os trabalhos e a convivência".

A realização de assembleias escolares não é recente e já existe há muito tempo em “escolas que se propuseram a criar espaços democráticos de participação de todos os indivíduos no processo de educação" (TOGNETTA; VINHA, 2007, p. 60). Além de não serem recentes, o que contraria a crença de que não passam de modismos passageiros (TOGNETTA; VINHA, 
2007), possuem não apenas uma função, mas várias. Puig et al. (2000, p. 87, 88) apontam as 6 funções principais das assembleias:

a assembleia, além de ser uma reunião para dialogar, [...] cumpre um claro papel informativo. Tanto as pessoas adultas de maneira vertical, como os alunos e as alunas de maneira horizontal podem utilizar o espaço para apresentar tudo o que consideram relevante. A assembleia também é uma reunião de análise do que passou. Em terceiro lugar, na assembleia se decide e se organiza o que fazer. [...] frequentemente, as assembleias servem de encontro com um certo caráter catártico. [...] finalmente, a assembleia é, simplesmente, uma possibilidade aberta que todos têm para apresentar o que desejam para a sua vida [...].

Além destas funções, os autores ainda apresentam outras secundárias, por assim dizer, que não anulam ou prejudicam as principais. As funções secundárias constituem-se no trabalho de algumas capacidades: colocar-se no lugar do outro; expressar as próprias opiniões com respeito, comparando-as com as dos demais colegas; compreender quais situações são problemáticas, comprometendo-se com sua melhora; apresentar argumentos lógicos, defendendo uma posição pessoal (PUIG et al., 2000).

Contudo, para que cumpram suas diversas funções, as assembleias precisam estar assentadas, de acordo com este autor, em algumas bases principais: a destinação de uma pequena parte do tempo semanal para sua realização; disposição de um espaço que favoreça o diálogo; interrupção do trabalho escolar habitual; uso do tempo para falar coletivamente sobre a dinâmica do grupo; dialogar com disposição para o entendimento, organização do trabalho e solução dos conflitos; e dialogar com disposição para mudar o que for preciso.

Quando se fala em assembleias de âmbito escolar, o nome de Ulysses Araújo surge frequentemente como uma das fundamentais referências, ao menos no Brasil. O autor afirma que existem 04 tipos de assembleias: de classe, de escola, docentes e fóruns (ARAÚJO, 2015). Tognetta e Vinha (2007), por sua vez, também consideram a mesma quantidade de assembleias, mas diferem da visão de Araújo, afirmando que os tipos são: de classe, de nível ou segmento, de escola e de docentes.

Trataremos aqui sobre as assembleias escolares como um todo, perpassando pelos tipos citados para que se tenha uma visão mais geral da temática, uma vez que juntas elas se complementam por meio de uma espécie de contínuo processo de retroalimentação (ARAÚJO, 2008). Contudo, o que realmente nos interessa são suas estruturas e funcionamento geral.

De acordo com Araújo (2015), as assembleias de classe tratam de temáticas relativas a cada sala de aula. Nesse sentido, delas participam os alunos da turma e ao menos um docente. Este tipo de assembleia pode ser realizado semanalmente, em encontros de uma hora de 
duração, e servem como espaço de diálogo na resolução dos conflitos cotidianos no âmbito de cada classe.

Já as assembleias docentes contam com a participação de todo o corpo de professores, da direção da escola e, sempre que possível, de um representante da Secretaria de Educação ou da mantenedora (ARAÚJO, 2008). Tal tipo de assembleia objetiva "regulamentar temáticas relacionadas com o convívio entre docentes e entre estes e a direção, com o projeto políticopedagógico da instituição e com conteúdos que envolvem a vida funcional e administrativa da escola" (ARAÚJO, 2015, p. 36).

Quanto às assembleias de nível ou segmento, englobam todas as classes de determinado nível ou segmento como, por exemplo, todas as turmas de $5^{\circ}$ ano de uma mesma escola. Este tipo de assembleia, que deve ser realizada mensalmente, visa a regulamentar "a convivência, as relações interpessoais, os conflitos, o uso dos espaços e os projetos em comum" (TOGNETTA; VINHA, 2007, p. 63).

Os fóruns, por sua vez, possuem uma composição bastante aberta, e contam com a presença de docentes, discentes, servidores, famílias e comunidade local, isto é, de toda a comunidade escolar, podendo ser realizados semestralmente (ARAÚJO, 2015). Têm como principal objetivo "articular os diversos segmentos da comunidade escolar que se disponham a atuar no desenvolvimento de ações mobilizadoras em torno de temáticas de cidadania no convívio da instituição de ensino" (ARAÚJO, 2015, p. 36).

Por último, e mais importante para nossa discussão, as assembleias de escola, que objetivam "regulamentar as relações interpessoais e a convivência no âmbito dos espaços coletivos" (ARAÚJO, 2015, p. 35). Este modelo de assembleia conta com a participação de todos os segmentos da comunidade escolar, com o intuito de discutir assuntos relativos a horários, espaço físico, alimentação e relações interpessoais, isto é, assuntos que extrapolam o âmbito das salas de aula (ARAÚJO, 2015).

As assembleias de escola possuem uma diferença fundamental em relação às demais, no tocante à participação, a qual ocorre por meio da representação, sendo que:

os representantes dos diversos segmentos são escolhidos obedecendo a uma sistemática de rodízio, de modo que, no transcorrer do tempo, todos os membros poderão participar das decisões coletivas. Sua periodicidade deve ser mensal, coordenada por um membro da direção da escola (ARAÚJO, 2015, p. 36).

Essa diferença se dá pelo fato de que não é positivo realizar assembleias com um elevado número de participantes, pois os profissionais que trabalham na escola possuem compromissos 
e horários a cumprir, conforme Araújo (2015). O mesmo autor apresenta procedimentos básicos para a realização das assembleias escolares: a mobilização do grupo, a sistematização da periodicidade, os conteúdos a serem tratados, a preparação e a composição da pauta, o registro por meio de atas e a coordenação e representação.

A mobilização do grupo é primeiro passo. Sem ela, a implementação das assembleias torna-se extremamente complicada, pois o grupo precisa compreender a "importância e os significados de se estabelecer os espaços de diálogo e participação" (ARAÚJO, 2015, p. 45). Os conflitos e diferenças fazem parte da vida e não podem ser eliminados, como muitos desejam, mas devem utilizados como matéria-prima para o desenvolvimento tanto pessoal quanto coletivo, e, por essa razão, logo no momento de mobilização deve ser esclarecido que, com as assembleias, os conflitos não serão eliminados, apenas mantidos em níveis democraticamente aceitos (ARAÚJO, 2015). Caso esse esclarecimento não ocorra, todo o processo de realização das assembleias pode cair em descrença.

Quanto à sistematização da periodicidade, Araújo (2015) afirma que uma das características que sustentam a democracia é a importância da regularidade nas normas que regem os espaços públicos, sendo esta uma das regras pétreas de uma constituição. A nossa Constituição Federal (1988) não difere do que diz o autor, pois possui algumas cláusulas pétreas, que são, por assim dizer, "sagradas". Tais cláusulas imodificáveis constam no art. 60 da Carta Magna brasileira (BRASIL, 1988):

\footnotetext{
$\S 4^{\circ}$ Não será objeto de deliberação a proposta de emenda tendente a abolir:

I - a forma federativa de Estado;

II - o voto direto, secreto, universal e periódico;

III - a separação dos Poderes;

IV - os direitos e garantias individuais.
}

Nesse sentido, é fundamental, de acordo com Araújo (2015), garantir a regularidade, quer dizer, a periodicidade das assembleias. O autor considera esse um dos temas "sagrados" na organização do trabalho, pois seu descumprimento acarreta sérias consequências, e sugere que, logo no início do ano, seja fixado um calendário com as datas de cada assembleia, que deve ser rigorosamente respeitado.

Os conteúdos a serem tratados nas assembleias são divididos, grosso modo, em dois grandes eixos: temáticas relacionadas ao "convívio escolar" - assuntos que afetam o coletivo; e às "relações interpessoais" - temas que afetam as pessoas de forma mais específica (ARAÚJO, 2015). Contudo, apesar de tais eixos necessitarem do enfoque principal, faz-se necessário: 
trazer para o cotidiano das assembleias os momentos prazerosos, falar de coisas positivas, felicitar as conquistas pessoais e coletivas e discutir os projetos futuros. Não se devem perder de vista esses aspectos durante as assembleias, sob pena de tratar de problemas públicos, renegando a importância da dimensão privada da vida e de nossos sentimentos mais sublimes para a construção ética nas relações (ARAÚJO, 2015, p. 54).

A preparação das assembleias é normalmente realizada nos dias que as precedem, isto é, na semana anterior. Nesse espaço de tempo, é construída a pauta a ser tratada, que pode ser dividida em dois grandes blocos: críticas e felicitações (ARAÚJO, 2015), que englobam os eixos de conteúdo supracitados: relações interpessoais e convívio escolar. A coordenação das assembleias é feita de forma rotativa, bem como sua representação. Quer dizer:

Os cargos existentes nas assembleias escolares e nos espaços que exigem representação não são fixos, mas rotativos, de modo que a coordenação e a representação do coletivo podem ser experenciadas pelo maior número de pessoas possível (ARAÚJO, 2015, p. 64).

Além dos procedimentos básicos para a realização das assembleias, o autor apresenta também como funcionam. Assim, as assembleias podem ser divididas em alguns momentos centrais, sendo que os três primeiros são de discussão da pauta.

O primeiro momento é de diálogo sobre o tema, no qual pode-se falar e também escutar o outro acerca dos assuntos postos em pauta:

É quando aparecem as diferenças, manifestam-se os valores, que cada um construiu para si em sua história de vida. Principalmente, é quando existe o confronto de posições e ideias. Tal confronto, nesse espaço organizado e sistematizado coletivamente, pode ser trabalhado de maneira democrática, evitando a forma violenta como geralmente é encaminhado no dia a dia das escolas (ARAÚJO, 2015, p. 69).

São construídas, no segundo momento, as regras de convivência, mas de forma contrária como geralmente é feito em grande parte das escolas: coletivamente, como pontua Araújo (2015, p. 70):

Encerrada a discussão de cada pauta, o grupo deve construir coletivamente a regra que regulará os conflitos inerentes ao tema. Assim, o coordenador da assembleia abre o espaço para que os participantes sugiram regras para o coletivo envolvido, competindo a ele cuidar para que a regra tenha uma redação adequada.

Vale destacar o importante alerta que Paro (2016) nos faz um sobre essa "abertura de espaço", a qual Araújo (2015) incumbe ao coordenador da assembleia o dever de realizar. Uma prática de participação não pode ser considerada democrática se esta participação depende de 
alguém que dê abertura para que ocorra, uma vez que a democracia não pode ser concedida, mas realizada, não podendo existir ditador democrático (PARO, 2016).

O terceiro momento, por sua vez, é de resolução de conflitos e de sugestões para o cumprimento destas regras coletivamente construídas e acertadas. Após solicitado pelo coordenador, as próprias pessoas apresentam propostas para que o problema não se repita ou ajudam o grupo e colegas a se conscientizarem acerca das consequências dos conflitos e a cumprir normas que foram coletivamente acertadas (ARAÚJO, 2015).

Já na parte final das assembleias, o autor sugere fazer duas coisas: reflexão sobre as felicitações apontadas, para que a assembleia seja finalizada de forma mais positiva; e a organização das ações a serem tomadas para a execução dos encaminhamentos dados.

\section{Assembleias estudantis: contribuições para o exercício da gestão democrática de uma escola pública de Manaus}

Antes de quaisquer discussões acerca das assembleias realizadas na Escola Municipal Liberdade e Ação ${ }^{3}$, faz-se necessária uma descrição e contextualização da instituição, mesmo que maneira geral. Localizada no bairro São Geraldo, zona centro-sul da cidade de ManausAM, a escola possui sua parte frontal para um dos muitos igarapés da cidade - atualmente numa obra que, para os moradores, parece sem fim - e, sendo assim, só é possível acessá-la por meio de duas ruas que se cruzam exatamente em frente à instituição.

Ao caminhar pelas ditas ruas em direção à escola, é possível perceber com facilidade uma mescla de casas de luxo com casas populares, que ficam lado a lado, deixando clara a disfunção social e a sociedade de classes existente na localidade. Contudo, pode-se dizer que tal abismo não surpreende, pois, há muito tempo, Souza (2017) denuncia a abissal desigualdade social brasileira, fruto, sobretudo, da escravidão, que nunca foi rompida, mas, sim, continuada de outras formas, algo comprovado pela existência de uma classe social de escravos modernos, provocativamente chamada de "ralé brasileira" pelo autor.

A escola possui atividades pedagógicas há mais 30 anos, tem capacidade para 226 alunos, característica própria de escolas que realizam educação em tempo integral e que necessitam de espaço para atividades diversificadas para o desenvolvimento integral dos sujeitos que a compõem. No período da reforma estrutural, apresentado na zona centro-sul, ocorreu um esvaziamento na escola em decorrência das obras do igarapé citado. Há alguns anos tal fato vem prejudicando a comunidade local, forçando seus moradores a residirem em outras

${ }^{3}$ Nome fictício, a fim de proteger os dados da escola e a comunidade acadêmica. 
áreas da cidade, o que também os direciona para efetivação de matrículas de seus filhos em outras instituições, embora, em vários casos, a escola tenha buscado fazer com que os alunos permanecessem, inclusive procurando diálogos com os setores do governo e empresas que realizam as obras.

Trata-se de uma escola dos anos iniciais que atende, em tempo integral, alunos que advém de diversas classes sociais, entrando às $07 \mathrm{~h}$ e saindo às $16 \mathrm{~h}$. Além de ser de tempo integral, o que já a diferencia de boa parte das escolas públicas existentes na capital amazonense, possui também a proposta de educação integral e uma perspectiva democrática de gestão escolar.

Diante dos aspectos apontados, fica clara a condição da escola em caminhar de modo contrário ao imposto que se reafirma nos planos econômico-social, ideológico, ético-político e educacional. Neste sentido, trata-se de permitir a construção da identidade dos sujeitos por meio da compreensão da realidade, reflexão e ação com base no estudo dos condicionantes da realidade social, envolvendo seus atores sociais por meio das assembleias (FRIGOTTO, 2103).

Antes do debate específico sobre as assembleias estudantis, vale ressaltar que elas não ocorrem de maneira isolada e/ou súbita. Existem processos anteriores e posteriores à sua realização. Quer dizer, previamente são realizadas assembleias em cada uma das classes, que contam apenas com a professora e com os alunos da turma. Posteriormente, busca-se pôr em prática o que fora decidido e a forma como isso acontece depende bastante do teor da decisão.

As assembleias estudantis contam com a coordenação da gestora da escola. Em sua ausência, foram coordenadas pela pedagoga, o que modificou bastante a dinâmica não apenas das assembleias, mas da escola como um todo (trataremos disso mais adiante). Também há a participação de boa parte do corpo docente e de todos os alunos da escola, desde os mais jovens até os mais velhos.

Os encontros são realizados de forma semanal, às quintas-feiras, por volta das $15 \mathrm{~h} 30$, estendendo-se até às 16h, horário de saída dos alunos. Em 2019, as assembleias passaram a ser realizadas às segundas-feiras, entre $13 \mathrm{~h}$ e 13h30. Pode-se dizer que, apesar dos esforços, na maioria das vezes, o tempo de duração das assembleias foi insuficiente, uma vez que 30 minutos é um intervalo bastante curto.

Além disso, por vezes as assembleias foram transferidas para outro dia e horário, ou, ainda pior, canceladas (algumas vezes, por de falta de energia no prédio, motivo fora do alcance de resolução da escola), ocorrendo somente na semana seguinte, o que prejudicava o andamento do trabalho, pois os espaços democráticos precisam ser respeitados, isto é, as pessoas precisam saber que o espaço e o momento do diálogo são garantidos (ARAÚJO, 2015). 
As assembleias da escola eram realizadas - com raras exceções, na quadra - em um espaço chamado "chapéu de palha", que carrega este nome justamente por sua estrutura assemelhar-se a tal adereço. $\mathrm{O}$ espaço possui um pequeno palco, onde quem coordena os encontros ou quem pede a palavra consegue ser visto de forma mais clara pelos demais, que ficam na parte de baixo, geralmente sentados no chão de concreto ou em cadeiras.

Embora pareça bastante pequeno à primeira vista, o local comporta todos os participantes das assembleias, ainda que precisem ficar de costas uns para os outros. Araújo (2015) argumenta que os participantes das assembleias devem ser capazes de ficar de frente uns para os outros, contudo, não foram percebidos grandes prejuízos para o andamento das assembleias devido a este fato.

Apresentada esta visão geral das assembleias da escola, trataremos mais especificamente de duas delas, com o intuito de demonstrar uma mudança percebida em sua dinâmica. Tal mudança ocorreu na passagem de ano de 2018 para 2019, e foi causada, sobretudo, pela ausência da gestora da escola, o que deixou, dentre outras coisas, a coordenação das assembleias a cargo da pedagoga: em 2018, todas as assembleias acompanhadas foram coordenadas pela gestora da escola; já em 2019, foram coordenadas pela pedagoga. Nesse sentido, apresentaremos uma assembleia ocorrida em agosto de 2018 e outra em abril de 2019.

Entendemos que a realização da assembleia requer o compromisso de todas e todos os sujeitos, independentemente de ausências das figuras de base que representam poder. É necessário compreensão e compromisso com a democracia, e fazer democracia significa experimentar debates e ações em função da liberdade e do atendimento ao direito de todas e todos.

A primeira assembleia foi realizada na quadra - espaço bem mais amplo do que o "chapéu de palha", porém bastante abafado -, sob a coordenação da diretora e com a participação do corpo docente e dos alunos. Foram tratados assuntos relacionados a um festival aberto à comunidade, que ocorreria na escola em algumas semanas. Os participantes discutiram coletivamente como tal evento ocorreria.

No festival em questão, a ideia era de que cada turma da escola ficaria responsável por uma barraca de venda de comidas variadas. Nesse sentido, na assembleia foi discutido principalmente se haveria algum tipo de classificação e premiação para as turmas que melhor se saíssem, isto é, que arrecadassem mais dinheiro.

Fica claro, neste episódio, que o viés da competitividade e da arrecadação de fundos para escola perfaz a natureza de uma sociedade formada nos princípios de igualdade, liberdade e propriedade, típico de uma sociedade de base liberal e neoliberal na qual se reflete a sociedade 
brasileira. Este processo refenda a discussão do capital humano, que traduz a escola na extensão da economia da educação (FRIGOTTO, 2013).

A modernização carrega em seus discursos democráticos e de gestão democrática as teorias de uma sociedade em ampla competição com o sentido de estender os domínios de "uma sociedade livre e democrática" sob a orientação do capital (FRIGOTTO, 2013).

Voltando ao ponto, diversas ideias - todas diferentes e até mesmo totalmente opostas foram apresentadas, em especial por parte dos alunos, que, como dito, são os principais personagens das assembleias da escola. Algumas professoras e a diretora também expuseram suas vozes. Essa multiplicidade de ideias é de extrema importância:

É apenas a exposição a argumentos opostos que pode permitir ao sujeito construir sua própria opinião. Ao se expor às razões conflitantes, o sujeito é instigado a perceber sua própria inclinação e quais argumentos lhe parecem mais justos e verdadeiros (SOUZA, 2017, p. 124).

Em espaços que se propõem a serem democráticos, a contraposição de ideias é algo considerado normal. Significa dizer que "não se podem perder de vista o direito e o respeito à diversidade, ao pensamento diferente. Esse princípio é uma das bases que sustentam as assembleias" (ARAÚJO, 2015, p. 17).

Na reta final da assembleia, após as discussões, alguns acordos foram firmados, com as melhores ideias escolhidas por meio do voto direto dos participantes, realizado de forma simples: apenas levantando a mão para concordar ou mantendo-a abaixada, caso discordasse. Contudo, em decorrência do curto tempo e dos problemas com a acústica da quadra, alguns pontos foram deixados para a assembleia seguinte.

Este processo de produção de consensos serve de base para que a comunidade escolar perceba seu mergulho na desordem neoliberal, com formas subliminares de violência imposta pelo mercado, o que torna a educação das maiorias um processo raso e desconexo da reflexão (GENTILI, 2013).

Apesar dos problemas, pode-se dizer que a assembleia em questão realizou progressos, embora pequenos, ao passo que a segunda nem tanto. Esta assembleia ocorreu na quadra, como dito, sem um planejamento e previa comunicação aos sujeitos, quer dizer, sua realização foi decidida a fim de garantir o processo, causando surpresa à comunidade escolar, e, por este motivo, contou com atraso de 20 minutos.

Esta concepção de assembleia, apenas para garantir o processo de participação democrática e sem prévio planejamento, revela também que, no espaço social, nem todos se apresentam dispostos a garantir as vozes sociais presentes na escola pública, é preciso lembrar 
que se trata de um campo diverso e que, portanto, concentra também pessoas em defesa do conservadorismo, ou seja, adeptos da decisão unilateral. É necessário conviver com este "diferente" e ao mesmo tempo garantir-lhe a participação social.

Após a organização das turmas na quadra e cumprimentar os presentes, a pedagoga perguntou quem gostaria de falar sobre as assembleias de sala, mas não obteve resposta. Neste momento, uma aluna pediu para ler um poema de Luiz Bacellar, ao passo que outra aluna o explicou aos presentes. Passado o ato, novamente a pedagoga repetiu a pergunta sobre as assembleias de classe, já demonstrando certa desconfiança de que não tinham sido realizadas. A suspeita da não realização logo foi confirmada pelos alunos, pois pouquíssimas turmas haviam realizado as assembleias de sala, o que prejudicou seriamente o andamento da assembleia estudantil.

Neste aspecto, revela-se o reducionismo da proposta de democracia e de assembleias, pois não valorizar este momento com as devidas características aponta um caminho de despolitização que se torna acirrado na sociedade neoliberal. Neste sentido, ao não dar valor ao processo reafirma-se a retórica conservadora de certos direitos, como o direito à propriedade $\mathrm{e}$ à liberdade de expressão (GENTILI, 2013).

Voltando a descrição da assembleia, a coordenação pedagógica entendeu que boa parte das turmas não as haviam realizado em sala, então a pedagoga pediu para que se manifestassem apenas as turmas que o fizeram. Algumas alunas pediram para falar, todavia, não foi possível entender suas vozes, pois a acústica da quadra mostrava-se ineficiente para a organização de mais de 150 pessoas que precisavam dialogar.

A ação da pedagoga, por estar próxima às crianças no momento em que falavam, era a de tentar "traduzir" o que salientaram em seus discursos. Uma das alunas sugeriu, como meio para diminuir os problemas do recreio, que este fosse dividido em dois: no primeiro momento, apenas para alunos do $1^{\circ}, 2^{\circ}$ e $3^{\circ}$ ano; e, no segundo, para os alunos maiores, do $4^{\circ}$ e $5^{\circ}$ ano. Quando posta em votação, a proposta foi aprovada, contudo, ficou definida a sua discussão de forma mais aprofundada na assembleia seguinte.

Resolvida esta questão, a mãe de um dos alunos solicitou uso da palavra. Ela apresentouse como nutricionista, portanto, queria falar sobre alimentação saudável, considerando que no dia 31 do mês anterior foi comemorado o dia da saúde e nutrição. Já na reta final da assembleia, a bibliotecária da escola, também presente, pediu para falar um pouco sobre os autores amazonenses com os quais vem trabalhando na biblioteca, e, em seguida, colocou a música "Floresta", de Ana Peixoto. Após este ato, a assembleia foi encerrada e todos retornaram às suas atividades normais. 
Independentemente das críticas e do resultado das assembleias, é importante destacar que a escola observada representa, para nós, um diferencial e que as contradições apontadas podem servir para aprimorar o processo democrático e permitir que as assembleias estudantis se tornem processos críticos de participação social e histórica de sua comunidade educativa.

A análise que pudemos fazer deste momento foi de uma prática educativa baseada na espontaneidade. Nela, "o intelectual não intervém, não direciona, cruza os braços. A ação se entrega quase a si mesma, é mais alvoroço, algazarra" (FREIRE, 2006, p. 46).

Isto revela que a figura da gestora da escola, que se encontrava de férias, ainda funciona, apesar das discussões sobre gestão democrática como ação de vigilância. Infelizmente a mudança de mentalidade é lenta e requer um querer reflexivo e comprometido de todas e todos.

Estes espaços comportamentais entre o que se pensa, o que se diz e o que se faz expressa a retórica da sociedade colonizada, são matizes idiossincráticas que são referendadas pelo liberalismo e neoliberalismo, e que forjam uma espécie de respeito às necessidades individuais, direitos individuais e competitividade.

É fundamental nas assembleias estudantis que a escola vá além de discutir suas funções e processos de relações internas. É necessário ver a sociedade como um todo, e a escola e sua comunidade escolar inseridas no processo de fazer parte da história do mundo. Não é possível pensar em assembleias estudantis sem a compreensão do mecanismo que organiza a sociedade (BORDIEU, 2014).

Em relação a este processo, ficou latente que a escola se redimensiona com a ausência da gestora. No período de férias, e durante a observação participante, foi possível perceber que a gestora é a principal responsável pela mudança ocorrida na escola nos últimos anos, e, em sua ausência, certos processos, como as próprias assembleias, perderam o ritmo e/ou deixaram de ser realizadas, o que demonstra necessidade de se propagar a cultura democrática na escola.

É essencial, portanto, o conhecimento das assembleias estudantis como instrumentos de liberdade, e realizá-las como bandeira derivada de uma sociedade democrática não a torna como tal. Para isso, é necessário desfigurar este processo equivocado de democracia, participação e coletividade. É fundamental lutar contra a instrumentalização da vida humana, forjada em funçã de preferências mercadológicas que produzem modelos de uma democracia inexistente.

Ressalta-se que as assembleias estudantis são de suma importância para a democratização das relações na escola, pois possuem como principal contribuição a possibilidade do diálogo e debate de questões e problemas comuns aos sujeitos da instituição escolar. Iniciar este processo e apresentar contradições não se configura como um problema, 
mas como possibilidade de mudança. Por isso, então, parabeniza-se aqui estes caminhos e tentativas democráticas de participação da sociedade.

\section{Considerações finais}

As assembleias estudantis são experiências de transformação da sociedade, e como tal, são necessárias à construção de uma democracia participativa e crítica, fundamental para as escolas públicas do país. O estudo desta realidade não se aplica às demais, porém permite-nos perceber, diante da totalidade histórica do mundo e dos domínios exercidos no Brasil, as implicações na educação e os processos de luta necessários à educação cidadã.

Neste sentido, as assembleias da escola, objeto desta pesquisa, fazem parte de um processo de democratização da instituição e de valorização das vozes de crianças num país em que, apesar da legislação expressa, não se respeitam sua presença e lugar no processo de construção de sua autonomia individual e coletiva.

Desse modo, parabeniza-se a perspectiva democrática de gestão escolar na instituição, pois representa uma das poucas a realizar estes processos, considerando que no Brasil as indicações para cargos de confiança ainda são numerosas na representação de poder e compõem grande porcentagem das relações liberais e neoliberais na sociedade.

As assembleias da escola pesquisada apresentaram uma série de problemas, que vão desde sua estrutura até a periodicidade. Apesar disso, suas atividades demonstraram contribuições para o processo de democratização, sendo que a principal delas, como pontuamos ao longo do estudo, foi a possibilidade do diálogo e do debate de questões e problemas comuns aos seus participantes, algo indispensável não apenas em escolas que se pretendem democráticas, mas para as sociedades.

Essas assembleias estudantis dão voz, mesmo que de forma tutorada, aos principais sujeitos da escola, seus alunos que, não raro, pouco ou nada são ouvidos pelos demais indivíduos escolares, algo que precisa ser constante e fortemente combatido, transformado.

\section{REFERÊNCIAS}

ADRIÃO, Theresa; CAMARGO, Rubens Barbosa de. A gestão democrática na Constituição Federal de 1988. In: ADRIÃO, Tereza; OLIVEIRA, Romualdo Portela de (orgs.). Gestão, financiamento e direito à educação: análise da Constituição Federal e da LDB. São Paulo: Xamã, p. 63-71, 2007.

APPLE, Michael; BEANE, James. Escolas democráticas. 2. ed. São Paulo: Cortez, 2001. 
ARAÚJO, Ulisses. Resolução de conflitos e assembleias escolares. Cadernos de Educação, Pelotas, n. 68, p. 115-131, jul./dez. 2008.

ARAÚJO, Ulisses. Autogestão na sala de aula: as assembleias escolares. São Paulo: Summus, 2015.

BOBBIO, Norberto. Dicionário de Política. Brasília: Editora Universidade de Brasília, 1998.

BOURDIEU, Pierre. Sobre o estado: cursos no Collège de France (1989-92). 1. ed. São Paulo: Companhia das Letras, 2014.

BRASIL, Constituição (1988). Constituição da República Federativa do Brasil. Brasília, DF: Senado, Centro Gráfico, 1988. 292 p.

BRASIL. Lei n. 8.930, de 6 de set. de 1994. Dispõe sobre os crimes hediondos, nos termos do art. 5o, inciso XLIII, da Constituição Federal, e determina outras providências. Diário Oficial da União, Brasília, DF, 7 set. de 1994. Disponível em:

http://www.planalto.gov.br/ccivil_03/leis/18930.htm. Acesso em 10 mar. 2020.

BRASIL. Lei n. 9.394, de 20 de dezembro de 1996. Estabelece as diretrizes e bases da educação nacional. Diário Oficial da União, Brasília, DF, 23 dez. 2996. Disponível em: http://www.planalto.gov.br/ccivil_03/leis/19394.htm. Acesso em 10 mar. 2020.

BRASIL. Lei n. 9.709, de 18 de nov. de 1998. Regulamenta a execução do disposto nos incisos I, II e III do art. 14 da Constituição Federal. Diário Oficial da União, Brasília, DF, 9 nov. 1998. Disponível em: http://www.planalto.gov.br/ccivil_03/leis/L9709.htm. Acesso em: 10 mar. 2020.

BRASIL. Lei n. 9.840, de 28 de set. de 1999. Altera dispositivos da Lei no 9.504, de 30 de setembro de 1997, e da Lei no 4.737, de 15 de julho de 1965 - Código Eleitoral. Brasília, DF, set. de 1999. Diário Oficial da União, Brasília, DF, 29 set. 1999. Disponível em:

http://www.planalto.gov.br/ccivil_03/leis/L9840.htm. Acesso em: 10 mar. 2020.

BRASIL. Lei n. 11.124, de 16 de jun. de 2005. Dispõe sobre o Sistema Nacional de Habitação de Interesse Social - SNHIS, cria o Fundo Nacional de Habitação de Interesse Social FNHIS e institui o Conselho Gestor do FNHIS. Diário Oficial da União, Brasília, DF, 17 jun. 2005. Disponível em: http://www.planalto.gov.br/ccivil_03/_Ato20042006/2005/Lei/L11124.htm. Acesso em: 10 mar. 2020.

BRASIL. Lei complementar n. 135, de 4 de jun. de 2010. Altera a Lei Complementar no 64, de 18 de maio de 1990, que estabelece, de acordo com o § 9o do art. 14 da Constituição Federal, casos de inelegibilidade, prazos de cessação e determina outras providências, para incluir hipóteses de inelegibilidade que visam a proteger a probidade administrativa e a moralidade no exercício do mandato. Diário Oficial da União, Brasília, DF, 7 jun. 2010. Disponível em: http://www.planalto.gov.br/ccivil_03/leis/lcp/lcp135.htm. Acesso em: 10 mar. 2020. 
BRASIL. Senado Federal. Projeto de iniciativa popular poderá contar com assinaturas eletrônicas, aprova CCJ. Disponível em:

https://www12.senado.leg.br/noticias/materias/2017/11/08/projeto-de-iniciativa-popularpodera-contar-com-assinaturas-eletronicas-aprova-ccj. Acesso em: 17 de jan. de 2019.

CORTELLA, Mário Sérgio. Uma vida entre livros: entrevista com mário sérgio cortella. [S. I.: s. n.], 2019. 1 vídeo (24 min). Disponível em:

https://www.nexojornal.com.br/video/video/Uma-vida-entre-livros-entrevista-com-MarioSergio-Cortella. Acesso em 15 de jan. de 2019.

DALBÉRIO, Maria Célia Borges. Neoliberalismo, políticas educacionais e a gestão democrática na escola pública de qualidade. São Paulo: Paulus, 2009.

DOURADO, Luiz Fernandes. A escolha de dirigentes escolares: política e gestão da educação no Brasil. In: FERREIRA, Naura Syria Carapeto (Org.). Gestão democrática da educação: atuais tendências, novos desafios. São Paulo: Cortez, 2013.

FERREIRA, Naura Syria Carapeto Ferreira (Org.). Gestão democrática da educação: atuais tendências, novos desafios. 8. ed. São Paulo: Cortez, 2013.

FORNAZIERI, Aldo. Plebiscito e referendo na história do brasil. Disponível em: https://www.fespsp.org.br/noticia/plebiscito_e_referendo_na_historia_do_brasil. Acesso em: 15 de janeiro de 2018.

FREIRE, Paulo. Educação e política. 7. ed. São Paulo: Cortez, 2003.

FRIGOTTO, Gaudêncio. Os delírios da razão: crise do capital e metamorfose conceitual no campo educacional. In: GENTILI, Pablo (org.); APPLE, Michel W (et al.). Pedagogia da exclusão: crítica ao neoliberalismo em educação. 19. ed. Petrópolis, RJ: vozes, 2013.

GADOTTI, Moacir. Gestão democrática com participação popular: planejamento e organização da educação nacional. São Paulo: Instituto Paulo Freire, 2013.

GENTILI, Pablo. Adeus à escola pública: a desordem neoliberal, a violência do mercado e o destino da educação das maiorias. In: GENTILI, Pablo (org.); APPLE, Michel W (et al.). Pedagogia da exclusão: crítica ao neoliberalismo em educação. 19. ed. Petrópolis, RJ: vozes, 2013.

GUTIERREZ, Gustavo Luis; CATANI, Afrânio Mendes. Participação e gestão escolar: conceitos e potencialidades. In: FERREIRA, Naura Syria Carapeto (Org.). Gestão democrática da educação: atuais tendências, novos desafios. São Paulo: Cortez, 2013.

HABERMAS, Jurgen. Problema de legitimación en el capitalismo Tardio. In: HABERMAS, Jurgen (org). Problema de legitimación en el capitalismo Tardio. Madrid: Cátedra. 1999. p. 80-86. Disponível em:

http://www.derechopenalenlared.com/libros/habermas_jurgen_problemas_de_legitimacion_e n_el_capitalismo_tardio.pdf. Acesso: 16 mar. 2020.

HASCKEL, Selita. Gestão democrática na educação infantil: tecendo a história da participação política dos professores nas creches e pré-escolas da rede municipal de ensino de 
Florianópolis. In: CARVALHO, Diana Carvalho de; QUINTEIRO, Juricema (orgs.).

Participar, brincar e aprender: exercitando os direitos da criança na escola. Araraquara, SP: Junqueira\&Marin: 2007.

LIMA, Licínio. Por que é tão difícil democratizar a gestão da escola pública? Educar em Revista, Curitiba, v. 34, n. 68, p. 15-28, mar./abr. 2018.

MARX, Karl. O capital: crítica da economia política. 21. ed. Rio de Janeiro: Civilização Brasileira, 2003.

MARX, Karl. O 18 brumário de Luís Bonaporte. São Paulo: Boitempo, 2011

PARO, Vitor Henrique. Gestão democrática da escola pública. 4. ed. São Paulo: Cortez, 2016.

PUIG, Josep Maria et al. Democracia e participação escolar. São Paulo: Moderna, 2000.

PUIG, Josep Maria. Assembleias de sala de aula ou como fazer coisas com palavras. ARGUIS, Ricardo et al. Tutoria: com a palavra, o aluno. Porto Alegre: Artmed, 2002.

QUINTERO, Juricema et al. Infância na escola: participação como princípio formativo. In: CARVALHO, Diana Carvalho de; QUINTEIRO, Juricema (orgs.). Participar, brincar e aprender: exercitando os direitos da criança na escola. Araraquara, SP: Junqueira\&Marin: 2007.

SOUZA, Jessé. A elite do atraso: da escravidão à lava jato. Rio de Janeiro: Leya, 2017.

SOUZA, Silvana Aparecida. Gestão democrática da escola e participação. In: SILVEIRA, Adriana Dragone. Gestão democrática, participação popular e controle social. Curitiba: Appris, 2015.

TOGNETA, Luciene Regina Paulino; VINHA, Telma Pileggi. Quando a escola é democrática: um olhar sobre a prática das regras e assembleias na escola. Campinas, SP: Mercado de Letras, 2007.

YIN, Robert. Estudo de caso: planejamento e métodos. 2. ed. Porto Alegre: Bookman, 2001.

\section{Como referenciar este artigo}

SARAIVA, Emerson Santos Silva; MONTE, Thalysson Kelvyn do. As assembleias estudantis e o exercício da gestão democrática. Revista on line de Política e Gestão Educacional, Araraquara, v. 24, n. 1, p. 164-188, jan./abr., 2020. e-ISSN:1519-9029. DOI: https://doi.org/10.22633/rpge.v24i1.13033

Submetido em: 09/10/2019

Revisões requeridas: 10/11/2019

Aprovado em: 15/12/2019

Publicado em: 06/01/2020 